\title{
Student Conduct @ NUS
}

\author{
Ang Siau Gek, Tan Peck Geok Esther, Chia Evelyn and Chan Ng Chye \\ National University of Singapore, Singapore
}

\begin{abstract}
The National University of Singapore (NUS), a widely respected institution of higher learning is dedicated to cultivating academic and personal excellence in a way that is inclusive and supportive where communal values as well as the dignity and rights of each person are respected.

In their educational pursuits in the University and in the course of everyday living, some students may at times, due to a variety of factors and circumstances, commit offences and violate certain rules \& regulations that have been made known to them during admission. As the management of student discipline is complex and ever changing, any institution attempting to handle student conduct would not be likely to find a 'one-size fits all' model that encompasses the principles of natural justice while addressing all the needs of the students, the staff and the University and yet finds itself applicable to the vast array of student offences being committed.

This paper discusses the changes observed in the nature of student misdemeanor cases at a publicly funded institution of higher learning in a fast developing city like Singapore, and shares how university policies and processes governing the handling of student discipline matters are evolving to better suit the present day environment that we are facing. The University notes that offences committed by the students over the years have evolved from the common low profile cheating cases to those that have garnered much public attention over the internet. Another area of concern is the growing number of academic offences over the years, namely plagiarism, which technology has made simple to commit and easy to detect. This paper will also cover what NUS will be putting in place to address the demands of managing the growing needs in student conduct management in the coming years.
\end{abstract}

\section{Introduction}

NUS has an average student population of 37,000 with about $71 \%$ Singapore citizens/permanent residents and $29 \%$ international citizens. The majority of these students, about $72 \%$, are registered in undergraduate degree programmes with the rest being Master or PhD students.

As an institution of higher learning, the National University of Singapore (NUS) is not only a place to acquire knowledge but it is also a vibrant campus that encourages its students to pursue their interests in activities outside the classroom. Educationally, NUS is committed to the expression and discussion of a diversity of ideas and opinions.

As a condition for admission, all registered students are required to sign an Acceptance Record in which they expressly declared having read and agreed to the University policies, undertakings and authorization requirements. Through the signing of the Acceptance Record, students are expected to comply with all the statutes, regulations, rules, codes of conduct and procedures as may from time to time be prescribed by the University. The Code of Student Conduct [1], which aims to guide student behaviour in both academic and non-academic aspects of University life, is included within the Acceptance Record. The Code of Student Conduct requires the student to maintain the highest standards of personal integrity and respect the rule of law, social order, and the rights of others as are expected of all members of the University, both within and outside the University as well as to uphold and maintain absolute academic honesty and integrity at all times.

\section{Challenges}

In recent years, NUS had experienced an increase in the number of contentious and high profile cases. The numbers are expected to continue rising with the widespread use of social media platforms such as Facebook, Instagram, Twitter and other online forums. Offences, such as the uploading of inappropriate contents or comments online, easily rouse public and media attention. Student discipline, in response, would have to manage this in an appropriate manner while considering the impact on the reputation of the University. It was apparent that most of the student offenders were not aware of the severity and implications of their actions. This prompted NUS to review the Code of Student Conduct, which subsequently included a section on adhering to an acceptable standard of behaviour in the use of digital and social media, be it on- or off-campus and even in a personal capacity.

In addition, NUS observed that the courts have witnessed a significant increase in the number of legal review cases where parties challenged administrative decisions made by institutions or tribunals. As individuals in our community become more aware of their rights, decisions made by our disciplinary bodies may be open to challenges in court. If NUS were 
confronted, our disciplinary procedures will be subject to scrutiny by the courts.

To ensure that our policies and procedures governing Discipline with Respect to Students are able to stand up to scrutiny, NUS decided to review all matters concerning student discipline and the resulting revisions to address the shortcomings that existed in the previous framework were implemented with effect from August 2013.

\section{Student Discipline: Review of Policies and Procedures}

As with most educational institutions, NUS has in place a structure and process for the adjudication of student offences. NUS manages student discipline based on the provisions of the Statute and Regulation on Discipline with Respect to Students (Statute 6 [2] \& Regulation 10 [3]) as well as the Code of Student Conduct. Hearings are conducted and offences penalised based on the powers accorded by Statute 6 to staff involved in the management of student discipline.

\subsection{Re-organization of Student Discipline Policy Framework}

During the review, it was found that while Regulation 10 was intended to be for procedural matters, it contained substantive provisions, such as empowerment to the Heads of Departments and Deans of Faculties to impose disciplinary sanctions. Statute 6 also contained a mix of substantive and procedural matters.

To accurately reflect each document's intended purpose and objectives and to maintain a clear distinction between substantive and procedural matters, all provisions relating to substantive matters such as the powers and jurisdiction of various disciplinary bodies were henceforth set out in Statute 6 , while procedural and administrative matters were contained solely in Regulation 10.

As the revisions on student discipline in August 2013 focused mainly on policies and guidelines, the structure for student discipline within the University remained largely unchanged.

\subsection{Definition of Student}

At NUS, a "Student" meant a person who has registered to study at or for a degree/diploma programme with the University, and has not completed the period of study, graduated, withdrawn from candidature, failed to satisfy any continuation requirement for the relevant degree or diploma, or been expelled as a result of disciplinary proceedings pursuant to Statute 6.

This definition however, did not cover persons who participate in NUS programmes and/or have access to NUS facilities and resources, but who are not formally registered with the University. As the review committee foresaw situations where NUS may want to take disciplinary action against such persons should they engage in conduct that threatens the interest or proper functioning of the University, specific to disciplinary matters, the definition of a "student" was broadened under Statute 6 to include such persons who are not formally registered with the Univresity. This gave NUS the discretion to take disciplinary action against a wider spectrum of people, should the need arise.

\subsection{The Board of Discipline (BoD) \& the Discipline Appeals Board (DAB)}

The Board of Discipline (BoD) which is the University level body that conducts hearings for student discipline is empowered to deal with all circumstances calling for disciplinary action and exercise any of the disciplinary powers as set out in Statute 6. The BoD is chaired by the Dean of Students, with faculty and student representation from the University's Senate Panel for Student Discipline and the Student Union.

Appeals against the decisions made by $\mathrm{BoD}$ are heard by the Disciplinary Appeals Board (DAB), which is similarly entitled to exercise any of the disciplinary powers set out in the Statute 6. The DAB is chaired by a member of the University's Board of Trustees, with faculty representation from the same Senate Panel. There are no student representatives on the DAB.

The Senate Panel for Student Discipline had previously consisted of up to 10 members elected from and by the members of the University Senate. As the number of disciplinary cases increased over the years, it became increasingly challenging to constitute the BoD to schedule disciplinary hearings. This was oftentimes compounded by the tight schedules of the Chair (i.e. the Dean of Students) and the limited number of members on the Senate Panel. In the revisions made in August 2013, the size of this Senate Panel was increased from 10 to 20 members, by allowing the President to appoint an additional 10 members. At the same time, the Provost now has the flexibility to appoint either the Dean of Students or a Vice Provost to chair the BoD. 


\subsection{Summary Action}

The Provost has the power to issue a 'Summary Action' against an offending student. This means that the Provost may summarily suspend or withhold any privilege, benefit, right, or facility as he may think fit against a student if the Provost has reason to believe that such action is necessary to:

(a) protect the interest of the University or any employee or student of the University; or

(b) ensure the proper functioning of the University.

Such a 'Summary Action' used to be final and binding on the student, giving him/her no opportunity to be heard or to address any allegation against him/her. The only recourse for the student was to make an appeal to the DAB and hope for a decision that sets aside the 'Summary Action'. This ran counter to the rules of natural justice. As such, in the revisions of August 2013, the 'Summary Action' was made an interim measure to be exercised by the Provost only in times of urgency where the sanctions imposed cannot be terminal (i.e. no dismissal or expulsion). Instead, a 'Summary Action' on a student would automatically lapse once a decision has been made by the BoD after a hearing for the student's offence. This ensured the student's right to a hearing before a $\mathrm{BoD}$, and his/her right to appeal to the $\mathrm{DAB}$, thereafter, against the BoD's decision also remains intact.

\subsection{Aligning Disciplinary Processes}

At the helm, the Provost makes decisions as to whether University-level hearings conducted by a BoD should be convened for student disciplinary cases deemed serious enough to be highlighted to him. If the Provost decides that the cases can be managed by the Faculties or Non-Academic Units, the cases are referred to the respective Deans and Heads for adjudication.

It was found that while the Regulation outlined the conduct of disciplinary proceedings before the BoD and the DAB it did not attempt to prescribe the same for the conduct of disciplinary proceedings before Heads and Deans. As part of adherence to principles of natural justice, the University sought to align its disciplinary process throughout to one which involves:

(a) Giving reasonable notice to the student of the complaint against him or her; and

(b) Giving a reasonable opportunity for the student to address the allegations levelled against him or her.

The revised process now prescribes that Heads and Deans should minimally provide notice of complaint and the opportunity to a hearing in their adjudication of cases.

\subsection{Aligning Disciplinary Configuration for Non-Faculty-Based Academic Units}

In general, any appeal against a decision made by the Head of a Faculty-based Academic Unit is adjudicated by the Dean of the corresponding Faculty.

Prior to August 2013, the existing disciplinary configuration for Academic Units was premised upon the structure of Academic Units residing within a Faculty or a School. There existed a gap in how disciplinary offences and appeals of students from non-traditional Academic Units - i.e. non-Facultybased Academic Units that did not report to a Dean, such as residential colleges - should be adjudicated. Provisions were subsequently made for the Dean of Students to hear the appeals from the decisions made by the Heads of these non-Faculty-based Academic Units.

\subsection{Establishing a University-level Unit}

As the secretariat to the $\mathrm{BoD}$ and $\mathrm{DAB}$ up to the point of the review, the Registrar's Office (RO) maintained minutes and records of all disciplinary hearings convened by the BoD and DAB. Such records allowed for the use of past cases as a reference for the consistent application of sanctions for similar cases. However, there was no reporting system for disciplinary matters adjudicated by the Heads and Deans.

One of the most significant outcomes of the review is the University's bold decision to re-define its long-term strategy such as to adopt a developmental approach in the holistic management of student discipline. RO was then identified as the incubator office to host an interim University-level Unit dealing with student discipline and conduct matters. In this interim, this Unit has been tentatively named, "Student Conduct Unit (SCU)".

With the establishment of the SCU, Heads and Deans can now report the outcomes of all disciplinary cases adjudicated by them to this centralized unit so that the University will be in a better position to supervise the administration of student discipline throughout the University. The immediate mandate of this Unit is to set up activities for maintaining parity in practices across the University and to ensure due process for all disciplinary offences in line with the principles of natural justice. The Unit will also review the workflow and procedures supporting and facilitating student discipline to ensure high levels of integrated and coordinated administrative support for managing student conduct. 
Table 1. Summary of Changes from a Review of NUS' Policies and Procedures on Discipline with Respect to Students

\begin{tabular}{|c|c|c|}
\hline CHANGES & BEFORE REVISION & AFIER REVISION \\
\hline $\begin{array}{l}\text { Re-organization of Student } \\
\text { Discipline Policy Framework }\end{array}$ & $\begin{array}{l}\text { - Statutes and Regulations } \\
\text { contained both substantive } \\
\text { and procedural provisions }\end{array}$ & $\begin{array}{l}\text { - Clear delineation between } \\
\text { substantive and procedural } \\
\text { provisions }\end{array}$ \\
\hline Definition of 'Students' & $\begin{array}{l}\text { - A person who is formally } \\
\text { registered for a programme } \\
\text { of study, whether degreed or } \\
\text { not }\end{array}$ & $\begin{array}{l}\text { - Include persons not formally } \\
\text { registered but partake in } \\
\text { programmes or have excess } \\
\text { to resources } \\
\end{array}$ \\
\hline $\begin{array}{l}\text { Expansion of the Senate Panel } \\
\text { for Student Discipline }\end{array}$ & $\begin{array}{l}\text { - Panel of up to } 10 \text { members } \\
\text { elected from and by the } \\
\text { members of the Senate }\end{array}$ & $\begin{array}{l}\text { - Expanded from } 10 \text { to } 20 \text {, by } \\
\text { allowing the President to } \\
\text { appoint an additional } 10 \\
\text { Senate members }\end{array}$ \\
\hline $\begin{array}{l}\text { Appointment of altemate } \\
\text { Chairman for BoD }\end{array}$ & $\begin{array}{l}\text { - Provision only for the Dean } \\
\text { of Students to be the } \\
\text { Chairman of the BoD }\end{array}$ & $\begin{array}{l}\text { - Provost has the flexibility to } \\
\text { appoint either the Dean of } \\
\text { Students or a Vice Provost as } \\
\text { the Chairman of the BoD } \\
\end{array}$ \\
\hline Summary Action & \begin{tabular}{|l|} 
- Final \\
Binding
\end{tabular} & $\begin{array}{l}\text { - Interim } \\
\text { - Only in times of urgency } \\
\text { - Cannot be terminal (i.e. no } \\
\text { dismissal or expulsion). } \\
\text { - Lapses once a decision has } \\
\text { been made by the BoD after } \\
\text { a hearing for the student's } \\
\text { offence }\end{array}$ \\
\hline $\begin{array}{l}\text { Aligning Disciplinary } \\
\text { Processes }\end{array}$ & $\begin{array}{l}\text { - No documented } \\
\text { requirements for proceedings } \\
\text { conducted by the Heads and } \\
\text { Deans }\end{array}$ & $\begin{array}{l}\text { - Heads and Deans should } \\
\text { minimally provide notice of } \\
\text { complaint and the } \\
\text { opportunity to a hearing in } \\
\text { their adjudication }\end{array}$ \\
\hline $\begin{array}{l}\text { Aligning Disciplinary } \\
\text { Configurations for Non- } \\
\text { Faculty-based Academic Units }\end{array}$ & - No documented provisions & $\begin{array}{l}\text { - Include provisions that will } \\
\text { adequately address such } \\
\text { Non-Faculty-based } \\
\text { Academic Units }\end{array}$ \\
\hline $\begin{array}{l}\text { Establishing of a University- } \\
\text { level Unit }\end{array}$ & $\begin{array}{l}\text { - No official unit managing } \\
\text { student disciplinary matters } \\
\text { - Only kept records of } \\
\text { hearings convened by the } \\
\text { BoD and DAB; no oversight } \\
\text { of outcomes of cases } \\
\text { adjudicated at decentralized } \\
\text { units } \\
\end{array}$ & $\begin{array}{l}\text { - Interim University-level Unit } \\
\text { set up } \\
\text { - Heads and Deans can now } \\
\text { report the outcomes of all } \\
\text { disciplinary cases } \\
\text { adjudicated by them to a } \\
\text { centralized unit }\end{array}$ \\
\hline
\end{tabular}

\section{Student Offences: Classification and Adjudication}

Before the review, Heads and Deans were empowered to deal with "Scheduled Offences" meaning any offence that did not involve or result in more serious offences like:

(a) Ragging (hazing);

(b) Acting in a manner that is or may be detrimental to the reputation, dignity, interest, or welfare of the University; and

(c) Criminal activity.

While this made it intuitively apparent that minor and less serious offences would be handled by the Heads and Deans, and serious cases would be adjudicated by the BoD and DAB, there was little or no clarity as to what constituted each of these categories of offences and what the appropriate and consistent penalties would be.

\subsection{Classification of Offences}

Following the review detailed earlier, NUS established these factors in deciding if an offence should be classified as Minor, Less Serious or Serious:

(a) The number of people involved in and/or affected by the alleged offence; (b) The degree of any inconvenience, harm or damage caused to person(s) or property;

(c) Whether the student concerned has been previously sanctioned by the University in respect of the same or similar offences;

(d) Whether the alleged misconduct could also violate or contravene any laws of Singapore;

(e) Whether any ragging was involved; and

(f) The extent to which the reputation, dignity, interest or welfare of the University may be affected or harmed.

These definitions were provided to the University community in the form of a set of "Guidance Notes". When in doubt about whether the offence should be classified as Minor, Serious or Less Serious, Faculties/Departments/Units may seek the advice of the Provost and the SCU.

Much consideration was given to the classification of offences that have garnered much public attention over the internet. Due to the impact of such cases on the reputation and welfare of the University as well as the degree of distress the public attention may cause to others, most of these cases tended to be adjudicated by the BoD.

The University is also in the process of reviewing its classification of offence severity and penalties issued for academic offences in efforts to provide greater clarity for staff and students on how academic offences are assessed and the consequences for committing these offences. With that, it will allow for consistency and alignment with other universities as well as holistic considerations for the approach to undertake in managing such offences.

\subsection{Adjudication Process for Serious Offences}

In accordance with the Statute and Regulation, serious offences are adjudicated by the BoD. The following flow chart shows the process from the point of notification of the alleged offence to the release of the outcome to the student offender. This process is still applicable with the revision of the policies and guidelines as it is aligned with the concept of natural justice which involves (i) giving reasonable notice to student of the complaint against him or her; and (ii) giving a reasonable opportunity for the student to address the allegations levelled against him or her. 


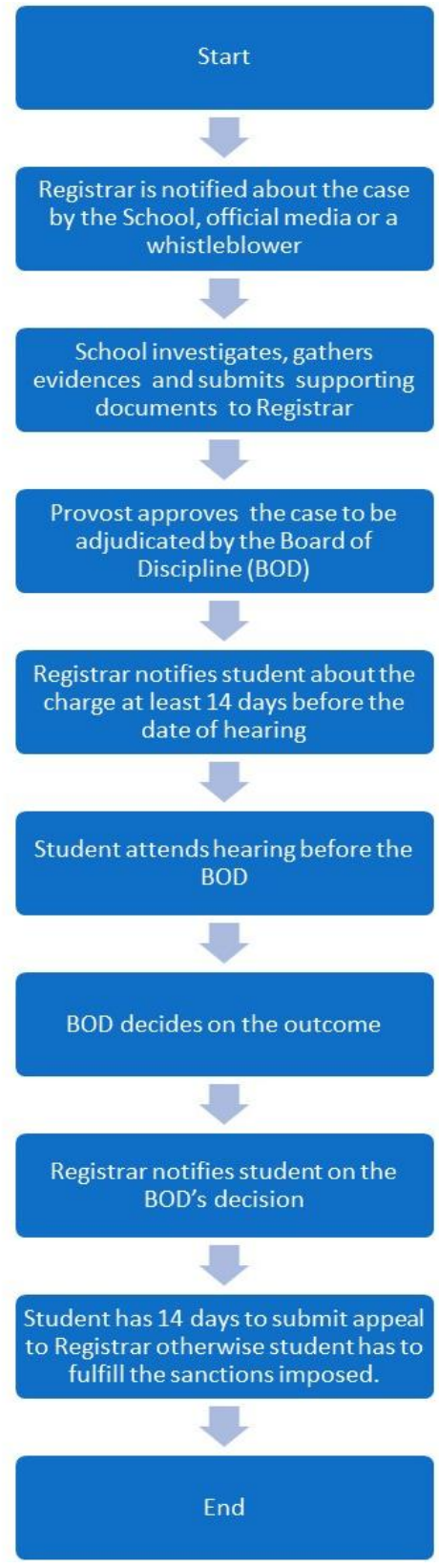

Figure 1. Process Flow for Adjudication of Serious Offences

Over the past few years, the BoD was convened to hear cases of students who were involved in serious offences. Some of these offences, e.g. cheating during exams, plagiarism and forgery of documents, tend to be recurrently common. But between 2012 and 2013, the BoD saw increasing numbers of cases involving the uploading or posting of inappropriate contents via social media platforms, many of which have attracted much public and media attention.

\subsection{Types of Penalties imposed by the Heads, Deans and BoD}

As with most other universities. Heads, Deans and the Board of Discipline are given a set of disciplinary powers to impose penalties on students who have committed offences. And as with many universities, the BoD may impose heavier penalties as compared to the Head and Deans due to the severity of the offences that tend to be adjudicated at by the BoD. The disciplinary powers of the different disciplinary parties are set out in Statute 6 and summarized in Table 2.

Table 2. Disciplinary Powers set out in Statute 6

\begin{tabular}{|c|c|c|}
\hline Penalties & $\begin{array}{c}\text { Heads of Academic and } \\
\text { Non-Academic Units and } \\
\text { Deans - Faculty/Department } \\
\text { level }\end{array}$ & $\begin{array}{c}\text { Board of Discipline (BOD) } \\
\text { and Discipline Appeals } \\
\text { Board (DAB) - University } \\
\text { level }\end{array}$ \\
\hline $\begin{array}{l}\text { Issuance of an order } \\
\text { including, as appropriate, a } \\
\text { requirement to comply with } \\
\text { specified conditions and a } \\
\text { statement of the sanctions } \\
\text { to be applied if such } \\
\text { conditions are not met }\end{array}$ & $\sqrt{ }$ & $\sqrt{ }$ \\
\hline $\begin{array}{l}\text { Issuance of a reprimand that } \\
\text { shall form part of such } \\
\text { person's official record }\end{array}$ & $\sqrt{ }$ & $\sqrt{ }$ \\
\hline Imposition of any fine & No more that $\underline{\mathbf{S} 1,0001-}$ & $\begin{array}{l}\text { No more than } \\
\mathbf{S} \$ 10,000 / \text { - }\end{array}$ \\
\hline Issuance of a public censure & $\sqrt{ }$ & $\sqrt{ }$ \\
\hline $\begin{array}{l}\text { Withdrawal and/or } \\
\text { suspension of any academic } \\
\text { privileges, benefits, rights or } \\
\text { facilities }\end{array}$ & $\begin{array}{l}\text { No more than } 1 \text { month; } \\
\text { and } \\
\text { May not suspend the right } \\
\text { to follow courses of } \\
\text { instruction or attend } \\
\text { examinations }\end{array}$ & $\sqrt{ }$ \\
\hline $\begin{array}{l}\text { Withdrawal and/or } \\
\text { suspension of any non- } \\
\text { academic University } \\
\text { privileges, benefits, rights or } \\
\text { facilities }\end{array}$ & $\begin{array}{l}\text { No more than } 2 \\
\text { semesters }\end{array}$ & $\sqrt{ }$ \\
\hline $\begin{array}{l}\text { Termination and/or full or } \\
\text { partial repayment of any } \\
\text { academic or non-academic } \\
\text { funding from the University }\end{array}$ & $\mathbf{x}$ & $\sqrt{ }$ \\
\hline $\begin{array}{l}\text { Expulsion from the } \\
\text { University }\end{array}$ & $\mathbf{x}$ & $\sqrt{ }$ \\
\hline $\begin{array}{l}\text { Deprivation and/or } \\
\text { withdrawal of any academic } \\
\text { distinction or grade to be } \\
\text { conferred or previously } \\
\text { conferred }\end{array}$ & $\begin{array}{l}\text { Only for assignments, } \\
\text { projects, or such other } \\
\text { forms of continuous } \\
\text { assessment }\end{array}$ & $\sqrt{ }$ \\
\hline
\end{tabular}

As previously mentioned, centralized recordkeeping, which includes capturing information on penalties imposed on student offences, now allow for the use of past cases to benchmark penalties for purposes of deciding on appropriate sanctions to impose. This creates more consistency and transparency throughout the University.

At the start of every academic year, the Chairman of the BoD would compile the list of offences adjudicated by the BoD and corresponding penalties for reporting to the Senate for consideration in their deliberations on educational policies within the University. In addition, as plagiarism is often a source of concern as it constitutes academic dishonesty, the 
Chairs of the Board of Undergraduate Studies (BUS) and Board of Graduate Studies (BGS) will share with their Boards the list of all plagiarism cases, including minor and less serious ones that have been adjudicated by Faculties, Schools and the BoD. This allows them to examine and make recommendations to the Senate concerning appropriate action on educational policies with reference to undergraduate and graduate studies respectively.

\section{New Developments in Managing Student Discipline}

The constant evolution of student offences and the increasing volume require regular reviews and developments in the management of student conduct. In the near future, the SCU has plans to further improve the processes and procedures for handling student discipline and to adopt new approaches for a more holistic model that will benefit students and the University alike.

The approach undertaken to improve the management of student discipline within the University shall comprise of refining certain existing processes and developing some new services.

\subsection{Further Improvements in Processes and Procedures}

Reviewing and Adapting Guidelines:

As previously mentioned NUS uses the 'Guidance Notes' as a reference for the purpose of administering student discipline. Contained in the 'Guidance Notes' are guidelines for the stratification of offences based on severity. In line with concepts of consistent and fair treatment, there is a need to conduct research to improve current guidelines for increased clarity and to align NUS with other established universities. This may be applicable now, more so than ever, with the recent increase in high profile cases and plagiarism given the widespread use of the internet.

Sharing Information on Penalties:

It is important for students to be fully aware of the possible consequences of committing offences and for staff to have access to information that allows for the benchmarking of penalties based on the offences committed. Having the penalties imposed on offences made known to staff and students is helpful for striving towards consistency and transparency in the imposition of punishments.

\section{Standardization of Procedures:}

The University strives for the investigative and adjudication procedures to meet certain requirements for quality assurance. As such, we often review and revise workflows and protocols to develop processes that are more consistent, efficient and seamless. To ensure the standardization and implementation of these processes throughout, the SCU strives to maintain integrative communication channels for consultation and regular updates on disciplinaryrelated matters through representatives/liaisons in the Unit, the Faculties and the non-Academic Units. This then creates accountability by allowing for checks on the compliance of units handling student disciplinary matters with disciplinary procedures and disciplinary guidelines. Non-compliant practices can then be identified and reported.

\subsection{Establishing a Centralized Database}

With quality assurance comes quality enhancements and the availability of a computerized Centralized Database accessible to all that manage student discipline can do just that. There are plans to start with designing a Complaints Management Portal to capture complaints and a Centralized Database to collate and store information on student offences, including the investigation and adjudication processes and the outcome of hearings. This will allow increased ease of access to student history, classification of offences and penalties imposed for use during assessments, investigations and hearings. The SCU, Faculties and non-Academic Units will be jointly responsible for collating and storing all information in this database.

Akin to what is likewise strongly propagated by the University of Lancaster in their efforts in maintaining a centralized registry for academic offences [4], the establishment of this database will improve the quality and process of managing student offences, it will allow for even more transparency and consistency and it will enable the use of the data collated for further reviewing and improvements of our mechanisms for handling student discipline in a large and dynamic university such as NUS.

\subsection{Greater Emphasis on Rehabilitation}

The growing number of student offences over time may be indicative that a system that focuses solely on deterring offences through punishment alone may not be completely effective. Increasingly, there are calls for the holistic management of student offences in educational institutions in the UK and USA [4] [5] [6] [7]. As with some universities like the University of Nottingham [8] [9] [10], which has developed their adjudication process to adopt a sympathetic view of students who have been incarcerated for criminal offences, NUS intends to eventually incorporate more holistic programmes as part of the disciplinary 
process. This places greater emphasis on the emotional and mental well-being of student offenders to facilitate their rehabilitation process. The SCU will collaborate with Faculties and non-Academic Units to improve existing or develop new programmes that can further support student offenders especially after offending and while they are at risk. These programmes can also serve as guidance programmes for students to create insights and to highlight any positive lessons learnt from their experiences undergoing disciplinary procedures.

\subsection{Prevention/Education}

A question researchers often ask is how much is it the responsibility of the students to know what constitute offences and why, and how much is it the responsibility of the educational institution to ensure that students understand [4] [6] [11]? An institution that focuses only on how often offences are being committed and how best to adjudicate and punish its students essentially sends the message that students are the ones primarily responsible for rectifying problems with student offences while the University's role should simply be to ensure a penalty system is in place should these students fail. Researchers similarly argue for educational institutions to ensure a culture within student-life that places emphasis on social and moral consciousness as well as academic integrity for all of its students [4] [5] [6] [7]. In addition to that, some researchers view it as the educational institution's responsibility to provide all students with skills and resources needed to avoid offending. This may be especially true for academic offences like plagiarism where students often report lacking skills and guidance when it comes to knowing what plagiarism is and how to avoid it [12]. Similarly the University has seen many student offences involving the uploading of inappropriate contents or comments online where most of the student offenders were not aware of the severity and implications of their actions and could not understand why they could be subject to disciplinary action for content posted on their personal webpages.

As with the holistic programmes that target the rehabilitation of offenders, the SCU aims to collaborate with the Faculties and non-Academic Units to eventually improve existing or develop new programmes that will educate students on what are offences and why they are offences. These programmes should also equip students with skills and direct them to resources that can help them to avoid offending. Staff, especially academic staff, may also be updated of the contents of the programme as they are often in the best position to provide guidance and inculcate values like academic integrity in students.

\section{Conclusion}

As an institution of higher learning, student-life in NUS is constantly evolving, with changes in cultures and technology having an impact on the volume and the types of student offences the University has to handle. It is up to us to continuously improve our policies and processes to adapt to and meet this growing need. And with this growing demand, the need to adapt is not just in terms of the procedures required to meet the demands, but towards a more holistic approach in looking at and managing student discipline, one that might prioritize the student experience and best outcomes for the student and ultimately for the University.

"Regulations are not just designed to punish but to 'rehabilitate the offender' i.e. to provide the means whereby they can avoid it in the future. This does not make institutions 'soft' but rather 'fair' and robust." [6].

\section{Acknowledgements}

Special thanks to Prof Tan Tai Yong and Low Zhiqi for the use of proposal titled Review of NUS' Student Disciplinary Process; Lim Jin Wei for the use of updates in 'Guidance Note' and Table 2.

\section{References}

[1] NUS Code of Student Conduct, http://www.nus.edu.sg/osa/images/osa/downloads/code_of_ student_conduct.pdf

[2] NUS Statute on Discipline with Respect to Students, https://share.nus.edu.sg/registrar/info/statutes/Statute06.pdf

[3] NUS Regulation on Discipline with Respect to Students, https://share.nus.edu.sg/registrar/info/statutes/Regn10.pdf

[4] Park, C., (2004): Rebels Without a Clause: towards an institutional framework for dealing with plagiarism by students. Journal of Further and Higher Education. Vol. 28, No. 3, pp 291-306, August 2004.

[5] Noguera, P.A., (2003): Schools, Prisons, and Social Implications of Punishment: Rethinking Disciplinary Practices. Theory Into Practice, Vol. 42, No. 4, pp 341-350, Autumn 2003

[6] MacDonald, R., \& Carroll, J., (2006): Plagiarism - a complex issue requiring a holistic institutional approach. Assessment \& Evaluation in Higher Education. Vol. 31, No.2, pp 233-245. 
[7] Cartledge, G., Tillman, L.C., \& Johnson, C.T., (2001):

Professional Ethics Within the Context of Student

Discipline and Diversity. Teacher Education and Special

Education. Vol. 24, No. 1, pp 25-37, Winter 2001.

[8] The University of Nottingham - Code of Discipline for Students,

http://www.nottingham.ac.uk/governance/documents/codeof-discipline.pdf

[9] The University of Manchester, Regulation XVII: Conduct and Discipline of Students,

http://documents.manchester.ac.uk/display.aspx?DocID=65 30

[10] The University of Edinburgh - Code of Student Conduct,

http://www.docs.sasg.ed.ac.uk/AcademicServices/Discipline /StudentCodeofConduct.pdf

[11] Park, C., (2003): In other (people's) words: plagiarism by university students - literature and lessons. Assessment \& Evaluation in Higher Education. Vol. 28, No. 5, pp 471488.

[12] Larkham, P.J., \& Manns, S., (2002): Plagiarism and its Treatment in Higher Education. Journal of Further and Higher Education. Vol. 26, No. 4, pp 339-349. 2002. 